\title{
LAS TRANSFORMACIONES DOCTRINALES DEL GREMIALISMO EN LA NEOLIBERALIZACIÓN DEL RÉGIMEN CÍVICO-MILITAR DE CHILE. 1973-1980
}

\author{
THE DOCTRINAL TRANSFORMATIONS OF \\ "GREMIALISMO" IN THE NEO-LIBERALIZATION \\ OF THE CIVIL-MILITARY REGIME IN CHILE. 1973- \\ 1980
}

\author{
Freddy Timmermann López \\ Universidad Católica Silva Henríquez
}

\section{RESUMEN}

Se analizan las transformaciones doctrinales que experimenta el gremialismo, partido político no oficial que apoya al Régimen Cívico-Militar que gobernó Chile (1973-1989), ante el predominio del neoliberalismo desde el año 1976, enfatizando los aspectos trascendentes de sus percepciones. Se trabajan documentos oficiales (Declaración de Principios del Gobierno de Chile, el Discurso de Chacarillas y Visión Futura de Chile) estableciendo macroformas textuales en contextos cambiantes de los escenarios de poder del RCM. De esta forma, se comprende la forma en que un régimen cívico-militar latinoamericano adopta históricamente el neoliberalismo y una Derecha tradicional conservadora se transforma en tecnocrática.

Palabras clave: gremialismo, trascendencia, principio de subsidiariedad, neoliberalismo, régimen cívico-militar.

\begin{abstract}
This paper analyses the doctrinal transformations experienced by "gremialismo" (an unofficial political party which supported the Civil-Military Regime that ruled Chile between 1973 and 1989) in view of the predominance of neo-liberalism from 1976 onwards, emphasising the transcendental aspects of its perceptions. Official documents are analysed (The Declaration of Principles of the Chilean Government, the Chacarillas Speech and The Future Vision of Chile) to establish textual macro-forms in the changing contexts of the CMR's power scenarios. This therefore provides an understanding of the manner in which a Latin American civil-military regime historically adopted neo-liberalism while the traditional, conservative right-wing turned to technocracy.
\end{abstract}

Keywords: "gremialismo", transcendence, principle of subsidiarity, Neo-liberalism, Civil-Military Regime. 


\section{INTRODUCCIÓN}

Chile es el primer país donde se aplica ampliamente un neoliberalismo que, en no menor medida, será posteriormente seguido por los gobiernos de Thatcher en Inglaterra y Reagan en Estados Unidos en la década del ochenta. Para comprender la forma en que un régimen militar latinoamericano adoptó tempranamente esta tendencia, se deben estudiar los presupuestos doctrinales de los grupos civiles que los asesoraron e implementaron el modelo, proceso que permite, además, ver la forma en que la Derecha chilena modifica, más allá de sus percepciones políticas, otros aspectos, en el contexto de un régimen militar que vulnera sistemáticamente los Derechos Humanos, instaurando el terror como un tipo específico de miedo que otorga una textura emocional distinta a la sociedad. Para ello, el artículo analiza las transformaciones doctrinales que experimenta el gremialismo -el partido político no oficial civil de Derecha que apoya al Régimen Cívico-Militar (RCM) que gobernó Chile desde el año 1973 ante el predominio del neoliberalismo desde el año 1976. Pertenecientes a la Derecha tradicional, adaptan sus pensamientos al neoliberalismo de Friedman y Hayek, desarrollado en Chile desde la Escuela de Economía de la Pontificia Universidad Católica de Santiago. Controlan los ministerios de Hacienda y Economía desde 1975 a 1981, y 1985 a 1989, constituyéndose en la nueva Derecha, tecnocrática, con un proyecto global de transformación del país. Los cambios mencionados se estudian enfatizando especialmente los aspectos trascendentes de las percepciones religiosas del gremialismo, en interrelación con aquellos inmanentes (políticos, económicos y sociales). Se trabajan documentos oficiales del RCM, redactados principalmente por su líder Jaime Guzman en su periodo fundacional, los años 1973-1980, como la Declaración de Principios del 11 de marzo, 1974, el Discurso de Chacarillas de julio de 1977 y Visión Futura de Chile, de abril de 1979. Mediante estudios de discurso, se establecen macroformas textuales y se proyectan análisis historiográficos sincrónicos y diacrónicos 
articulados por los documentos mencionados, cambiantes por las transformaciones de los escenarios de poder del RCM. De esta forma, el trabajo refiere en la Historia Reciente de Chile el proceso mediante el cual la Derecha tradicional conservadora se transforma en tecnocrática, articulando al mismo tiempo con ello una modificación de las formas capitalistas que se aplican mediante cambios en sus doctrinas, en que las tensiones entre los aspectos trascendentes e inmanentes se resuelven a favor de una mixtura que impone un esencialismo económico que desplaza, sin desconocerlo sin embargo, uno integrista católico.

\section{Gremialismo y neoliberalismo}

La elite de potenciales colaboradores con las FFAA que toman el poder tenía que sincronizar con ciertos elementos de su mentalidad, como poseer un intenso nacionalismo, entendido como el fenómeno de la armonía y de unidad respecto a la propiedad privada de los individuos; un sentimiento empático con los valores del integrismo valórico; eficiencia y pragmatismo en la acción, así como jerarquía y disciplina en la organización. Estas eran, con diferentes matices y acentos, las fórmulas propuestas por sectores de la Derecha (Cañas, 1997: 64, 65), quienes se integran mayormente como "equipo", "capaz de contrarrestar ciertas tendencias del mundo militar y ofrecer, al propio régimen, un proyecto determinado", aportándolo a una empresa política común, que deja así de ser definida como puramente militar y pasa a ser "cívico-militar" (Arriagada, 98: 77). Eran los Chicago Boys, los gremialistas de Jaime Guzmán y los profesionales que habían participado en el gobierno de Jorge Alessandri. El movimiento gremialista había surgido como la principal organización de masas para oponerse a la UP. El acento corporativista económico de su discurso obedece al intento de generar una alianza entre las capas medias independientes y las tradicionales dominantes en la lucha contra la UP para superar las "divisiones artificiales" de las ideologías y los partidos políticos (Vergara, 1985: 60). Fue el grupo más influyente entre los años 1977 y 1980, favorecidos por la presencia del general Sergio Covarrubias como jefe del Estado Mayor Presidencial y de Sergio Fernández como ministro del Interior (Valdivia, 2003: 201). Tenían un discurso político que provenía en lo principal del tradicionalismo católico de raíces hispanas y de carácter integrista. Privilegiaban un orden social sometido a las jerarquías e inspirados en concepciones originales acerca de la nación, la autoridad y el "poder social" a partir de algunas ideas de la filosofía española del corporativismo. Participan en la redacción de documentos oficiales del RCM, como la Declaración de Principios de la Junta de Gobierno (1974), el Discurso de Chacarillas (1977), Visión Futura de Chile (1979) y la Constitución de 1980. Jaime 
Guzmán es posiblemente el asesor que está más tiempo cercano a Pinochet en el período en estudio. Es el principal redactor de la Declaración de Principios (Cristi-Ruiz, 1992: 37). También lo hace con la mayoría de los discursos más importantes y elaborara minutas con recomendaciones políticas y propuestas ideológicas que señalaban la orientación política del régimen (Huneeus, 2001: 17).

La acción coordinada de gremialistas y neoliberales en el RCM recoge un pasado donde los elementos religiosos, políticos y académicos coinciden en medio de tres coyunturas históricas: la irrupción de la Democracia Cristiana en la década del sesenta, la oposición a la Unidad Popular en el inicio de los setentas y la colaboración con el RCM. Elementos religiosos, especialmente provenientes de sectores ortodoxos católicos, otorgan influencia a Guzmán, que transformó la religiosidad en una actividad complementaria a la capacitación política de los jóvenes adherentes al gremialismo llegando a impartir cursos de religión (Huneeus, 2000: 378).

Para la Derecha, el neoliberalismo introduce modificaciones en su forma histórica de hacer política, porque los conservadores sólo defendían lo existente, rechazando la lógica revolucionaria, el cambio social, la modernización, sin asignar importancia a las funciones ideológicas de la política. El neoliberalismo, en cambio, es revolucionario, quiere refundar la sociedad, tiene una visión utópica de una sociedad autorregulada por el mercado. Sus estrategias ideológico-culturales desempeñan un papel crucial.

Desde 1978, se diseñan y ejecutan estrategias para sensibilizar al hombre medio y a las elites por medio de un discurso racional sobre la construcción de una nueva sociedad utilizando políticas concretas y planes de reforma. Se usaban medios de comunicación de masas como el diario El Mercurio y las revistas Qué Pasa, Ercilla, quienes en sus líneas editoriales popularizaban los conceptos neoliberales. Se difunden las realizaciones alcanzadas, los éxitos y las "modernizaciones" enfatizándose su eficacia y ciertos liderazgos, como el de los alcaldes en reemplazo del anterior político. Forman de elites y cuadros políticos, asociados a los gremialistas. Se crean revistas de tipo ideológico-político como Realidad en 1979 y Estudios Públicos en 1980; y centros de estudio, como el Centro de Estudios Públicos en 1980. Se adquieren y controlan organismos académicos y centros de investigación. Se generan "corrientes de opinión", como en 1979 el Grupo Nueva Democracia, ligado al gremialismo universitario, que vincula a quienes elaboraron la Declaración de Principios con los neoliberales, participando en el debate institucional desde las posiciones de estos últimos. La Corporación de Estudios Contemporáneos se crea en 1978 y estaba vinculada a la Derecha tradicional (Vergara, 1985: 173-175). 
Los Chicago Boys fueron favorecidos al implantarse un orden político con un bajo nivel de institucionalización, lo que les otorgó una "enorme libertad para actuar y para imponer sus decisiones sin interferencias de otros órganos de poder". Ninguna de sus reformas económicas fue examinada previamente por el Consejo de Estado y sólo hasta 1977 tuvieron la oposición del general Leigh en algunos puntos específicos; contaron con una prensa favorable a sus planteamientos que difundió positivamente sus iniciativas escondiendo sus debilidades, silenciando las críticas de ciertos círculos empresariales y opositores; actuaron en un escenario político simplificado sin la oposición de los trabajadores, sindicatos y partidos políticos (Huneeus, 2000: 56, 73, 248, 249). Los favoreció que el RCM comenzó a experimentar un desarrollo económico positivo (Meller, 1998: 198-217). Se comenzó a hablar de un "milagro económico", creando la imagen de que se crecía al doble del ritmo histórico y que se rompería la barrera del subdesarrollo en 1992. Este optimismo se extendió a amplios sectores de las capas medias, pues la expansión del gasto debida a la llegada de capitales externos inundó el mercado nacional de bienes importados accesibles debido a los créditos de consumo existentes (Vergara, 1985: 177-191). Sin embargo, la opción a favor de una economía neoliberal no determinó mecánicamente las concepciones ideológicas existentes en otras esferas de acción del RCM, aunque sí redefinió los parámetros ideológicos al interior de los cuáles era posible moverse.

\section{La Declaración de Principios de la Junta de Gobierno}

Los militares no podían gobernar solos. Había áreas en que requerían de los civiles y era importante que estos conocieran hacia donde se caminaba luego de superada la natural improvisación al instalar un régimen radicalmente distinto. En ese contexto, ante la carencia de una hegemonía en el RCM, se elabora la DP, en momentos en que culmina el último ciclo secular que Braudel establece para la historia de Europa, donde, "Todos los cimientos de la vida económica, todas las acciones de la experiencia, presentes y pasadas, están en tela de juicio" (1984: 55-59). Para percibir la transformación del pensamiento gremialista, se analizarán los elementos trascendentes de la DP y su relación con aquellos inmanentes ${ }^{1}$ como la

1 En la inmanencia, el ser queda inscrito en lo experimentable o finito y su realización o ejercicio no pone al efecto como existente fuera de ella, donde el viviente es a la vez agente y paciente o sujeto actuado. Trascendencia son las experiencias que sobrepasen los límites que señala la inmanencia (Pellegrino, 1983: 543-555). 
política (proceso de institucionalización, poder social, principio de subsidiariedad), la economía y el Estado².

\section{1. Trascendencia e inmanencia}

La "tradición" que se sigue es "cristiana", para oponerla a la "sociedad de inspiración marxista" (9). Se afirma que Chile no desea pertenecer a las "sociedades desarrolladas de Occidente" porque esto genera un "vacío interior" y que desea "satisfacer" "las inquietudes espirituales del ser humano"; que el hombre es "entendido" "como un ser dotado de espiritualidad" (11). Se ven las relaciones del Estado con estos preceptos (13-20), especialmente el "Bien Común", tema central que vincula la "concepción cristiana" con el "Estado", dotándola de una operatividad en la inmanencia al tratar el Principio de Subsidiariedad (16-20) y, más aun, cuando se vincula con la actividad económica, siempre advirtiendo al Estado el respeto que debe tener por los elementos trascendentes. El orden jerárquico es vertical y horizontal:

\begin{tabular}{|l|l|c|}
\hline \multicolumn{1}{|c|}{1} & \multicolumn{1}{|c|}{2} & 3 \\
\hline Espiritualidad del Hombre & & Estado \\
\hline Bien Común & $\begin{array}{l}\text { sociedad- } \\
\text { economía }\end{array}$ & Estado \\
\hline $\begin{array}{l}\text { Principio de } \\
\text { Subsidiariedad }\end{array}$ & $\begin{array}{l}\text { sociedad- } \\
\text { economía }\end{array}$ & Estado \\
\hline
\end{tabular}

Son los principios trascendentes (1) los que enmarcan la proyección de las tareas inmanentes (2), y ello debe ser respetado por el Estado (3).

La "nueva y moderna institucionalidad" no es tratada en función directa de elementos trascendentes y al analizar el "desarrollo económico" sus elementos aparecen casi indirectamente (15). Tampoco, el "vacío" en el "espíritu" del "hombre" que dejan las "sociedades de consumo" (35-36), el papel de la "educación" para superar lo anterior al "fomentar" "una escala de valores morales y espirituales propios de nuestra tradición chilena y cristiana" (36) y la percepción de la "mujer" como "la roca espiritual de la Patria" (38). 


\section{2. La Concepción Cristiana y el Estado}

Se enfatiza un absoluto trascendente, la "concepción cristiana", que opera en la inmanencia, pudiendo extraviarse pero también recuperarse, lo que permitirá "robustecer su conocimiento y amor" (36). Se valida al expresar que "dio forma a la civilización occidental", "de la cual formamos parte". También en que "es su progresiva pérdida o desfiguración la que ha provocado, en buena medida, el resquebrajamiento moral que hoy pone en peligro a esa misma civilización". Se expresa que "entendemos al hombre como un ser dotado de espiritualidad" lo que sirve para establecer un "fundamento" de "la dignidad de la persona humana", lo que "se traduce" en varias "consecuencias" (13). En la primera, se sostiene que "[e]l Hombre Tiene Derechos Naturales Anteriores y Superiores al Estado", "derechos" que "arrancan de la naturaleza misma del ser humano" al poseer un origen "en el propio Creador" (13). El poder del Estado es limitado, pues los derechos mencionados "no siendo él quien los concede, tampoco podría jamás negarlos", aunque "debe reconocerlos" y "reglamentarlos", lo que implica ponerlos en la historia según su poder, dejando latente la posibilidad de desconocerlos y de manipular la percepción de "espiritualidad". La segunda "consecuencia", "El Estado Debe Estar al Servicio de la Persona Y No Al Revés", es, prácticamente, una redundancia, más fundamentada, de la anterior: "[ $t$ ]anto desde el punto de vista del ser como desde el punto de vista del fin, el hombre es superior al Estado" porque "desde el ángulo del ser" "mientras el hombre es un ser sustancial, la sociedad o el Estado son sólo seres accidentales de relación". Por lo anterior, "puede concebirse la existencia temporal de un hombre al margen de toda sociedad" pero "es inconcebible, siquiera por un instante, la existencia de una sociedad o Estado sin seres humanos". Agrega que el hombre "tiene prioridad" "desde el prisma del fin, porque mientras las sociedades o Estados se agotan en el tiempo y en la historia, el hombre los trasciende, ya que vive en la historia, pero no se agota en ella" (14). En la tercera consecuencia se resaltan los atributos básicos que deben rodear el "Bien Común": un equilibrio entre el individualismo y la solidaridad social y la consideración de "los dere-

2 Posteriormente, se analizará la variación de elementos de la Declaración de Principios (DP, en adelante) en el Discurso Chacarillas de 1977 y Visión Futura de Chile de 1979. El primero, DCH en adelante, caracteriza la "nueva democracia", estableciendo la gradualidad temporal en que esto se implantará. Se da a conocer en julio de 1977. El segundo, VFCH, en adelante, expone una "Clase magistral" del general Pinochet en la inauguración del año académico en la Universidad de Chile, el 6 de abril de 1979. En todas estas fuentes se citará inmediatamente en el texto, entre paréntesis, la página donde figura su contenido. 
chos naturales de la persona humana" (15). El hombre es percibido como individuo cuando se define "el bien común general", precisando que este alcanza "a cada uno de los chilenos", pero pensando en "las condiciones sociales" que permitan "alcanzar" una "plena realización personal". En cambio, aquel individuo que aparece en "el individualismo liberal", en términos económicos en cuanto al "consumo" (10), no es bien visto pues el "bien individual" se trata de obtener "con la total prescindencia del de los demás" (14-15). También porque el "materialismo" "corroe" a las llamadas "sociedades de consumo [y] denuncia la existencia de un bienestar que más que ayudar a la perfección integral del hombre lo someta a una carrera que lo domina, en pos de una riqueza que al final deja vacío su espíritu. Que más que liberarlo lo esclaviza" (10,35-36).

El bien del país es percibido de esta forma como un elemento valórico trascendente. No se olvida lo que antes se enunció en el octavo párrafo de la tercera "consecuencia" del capítulo II, una de las dos necesidades del Bien Común, la solidaridad social. También, indirectamente, pone en manos del Estado el reconocimiento de la otra necesidad, los derechos naturales del hombre. Sin embargo, más adelante, ya en el terreno inmanente de la política y la economía, siempre con la base trascendente mencionada, no se permite que el Estado perturbe al "individuo liberal" al expresar que este debe poseer "un ámbito de vida y actividad propia independiente", "sólo [siendo] sometido al superior control de éste desde el ángulo del bien común, donde reside la fuente de una vida social en que la libertad ofrezca a la creación y al esfuerzo personal un margen de alternativas y variedad suficientes" (17-18). Después de ello, trata un subcapítulo extenso titulado "El Respeto al derecho de Subsidiariedad Supone la Aceptación del Derecho de Propiedad Privada y de la Libre Iniciativa en el Campo Económico" (18-20), la quinta consecuencia. Así, el individuo posee una plena libertad económica de acción siempre que respete el principio de solidaridad social (15). Por ello se afirmará que no se admite "otra fuente de desigualdades entre los seres humanos que las que provengan del Creador o del mayor mérito de cada cual" (24) pues no se "excluye" el "sano espíritu de competencia entre los que desarrollan una misma tarea" sino que esto se debe "fomentar" "como un valioso instrumento de empuje colectivo" $(24-25 ; 34)$. El individuo perfilado en el documento está enmarcado por una noción de trascendencia que lo obliga en función de cumplir una virtud en la que está implícita una vida proyectada más allá de la histórica. También, está enmarcado por una noción de inmanencia -política, economía- que recoge lo anterior, imponiendo determinados límites, siendo el Estado quien se encarga de velar por su cumplimiento y la conciencia de cada uno en lo económico. Entonces, en rigor, el único individuo libre que existe en la De- 
claración de Principios es el "liberal", en su lectura económica de actividad económica y de consumo.

En la cuarta consecuencia, el bien común exige respetar el "Principio de Subsidiariedad", quedando en evidencia un temor a un Estado que no sea estrictamente controlado por principios no cristianos, a un poder que de hecho se aparte de ellos. Se cuida no limitar los poderes de la Junta Militar, que controla el Estado. Al contrario, los legitima indirectamente al expresar que el Estado asume en la acción el campo de las sociedades menores "por razón del bien común", es decir, de Dios (17).

\section{3. - Principio de Subsidiariedad y el Bien Común}

La política es severamente condenada, afirmándose que "enriquece" materialmente (28), es "demagógica" imponiendo "recetas ideológicas" (24) y, en la "administración pública" generó sectarismo, ineficiencia" (25). El "partidismo" es mal visto $(25,29$ y 30$)$ y, se agrega, "[n]o puede permitirse nunca más que, en nombre de un pluralismo mal entendido, una democracia ingenua permita que actúen libremente en su seno grupos organizados... cuyo objetivo es construir un Estado totalitario" (27). Se piensa que espacio social es "diverso" y posee "valores y formas de vida" que "están en tela de juicio" "en los momentos en que una profunda crisis conmueve al mundo" (9). Se divide el contexto externo del país en "dos tipos antagónicos de sociedades": "las sociedades llamadas socialistas e inspiradas en el marxismo leninismo" y "las naciones más avanzadas de Occidente". Ambas son rechazadas. La primera, "por "su carácter totalitario y anulador de la persona humana" pues ello "contradice nuestra tradición cristiana e hispánica" (9). Se afirma que Chile es moralmente superior a las "sociedades de inspiración marxista" y "Occidentales", al expresar que "la verdadera idea de bien común [que se sostiene] se aparta de ambos extremos, y los supera" (15).

Proyectar justicia social, solidaridad y bien común es central para articular la política. Éste último es "un bien de orden o de relación" pues "hace que la obtención del bien individual de cada uno exija para ser verdaderamente tal una preocupación y respeto solidario y activo por el bien de los demás", lo que "descarta la concepción liberal". También, "parte del reconocimiento de los derechos de la persona humana" negando "que en nombre de un falso "bien común" pudiera llegar a ser admisible su conculcación". El "bien común no es el bien del Estado", ni de "la mayoría y mucho menos es el de una minoría" (15), es "el conjunto de condiciones que permita a todos y a cada uno de los miembros de la sociedad alcanzar su verdadero bien individual". Se centra en la obtención de un "bien 
individual" o "realización personal", "no de algunos" sino de "todos o cada uno" (15). Es relacionado con los "derechos naturales", lo que puso límites a la acción del Estado. Debe "respetar el principio de subsidiariedad". Jerarquiza dos órdenes: las sociedades mayores existen -"se van formando"- "para satisfacer fines que las menores no puede alcanzar por sí solas". Sobre estas últimas sostiene que "da[n] vida... a diversas formas de agrupación social más amplias, para lograr objetivos que... [son incapaces] de conseguir por sí". Son las "sociedades intermedias", las que finalmente llegan "a integrar[se]... en un Estado" "por la necesidad de que haya un orden común a todas ellas que las coordine en justicia y que asuma las funciones que ninguna de aquellas podría cumplir directamente". Luego, se refiere a los límites que cada "sociedad mayor" tiene, en cuanto "acción" respecto a la "sociedad menor". Expresa que "no le es legítima la absorción del campo que es propio de la menor, y dentro del cual ésta debe tener una suficiente autonomía"; que "[l]a órbita de competencia de la sociedad mayor empieza donde termina la posibilidad de acción adecuada de la menor" (17). Lo expresado constituye la "idea matriz" del principio de subsidiariedad (16, 17). Los "gremios" se perciben como "agrupaciones" de las "sociedades intermedias entre el hombre y el Estado", de "particular importancia". Pueden ser "laborales, empresariales, profesionales o estudiantiles". El principio de subsidiariedad "exige" que se "desenvuelvan con autonomía dentro de sus fines específicos, sin que el Estado absorba su control"; "tampoco puede admitirse que sus objetivos sean distorsionados por una instrumentalización partidista de ellos o sus directivas" (30). Es decir, su acción es protegida del Estado, pero limitada en su gestión por un control de sus "objetivos", que deben "apolíticos". Esta "despolitización "es el único camino posible para que los gremios y demás organizaciones intermedias sean auténticos vehículos de participación social" (30). Es el "nuevo sentido de gremio". Su "más primaria razón de ser" es la "defensa de sus agremiados", las "personas ligadas por actividades e intereses comunes" (31).

Se expresa que el principio de subsidiariedad "representa la clave de la vigencia de una sociedad auténticamente libertaria", que es "el barómetro principal para medir el grado de libertad de una estructura social" y su "vigencia" (17). Luego, establece el polo opuesto, el "estatismo", que afecta negativamente la libertad social, "por extendido que sea el derecho ciudadano de los derechos políticos", con lo que menoscaba la percepción de libertad que la noción de democracia anterior otorga. La libertad que se valida es aquella que se genera al poseer un "ámbito de vida y actividad propia independiente del Estado", siendo sometida "al superior control de éste desde el ángulo del bien común". Es decir, la causa prima- 
ria de la libertad social es la "concepción cristiana", Dios, lo que anula la autonomía del hombre para diseñar sus principios básicos de convivencia social y, con ello, el control de quienes ejercen el poder. Se establece un vínculo con el ámbito económico al sostener que "[n]o cuesta advertir que el principio de subsidiariedad presupone el derecho a la libre iniciativa en el campo económico"; que "[l]a posibilidad de que los particulares puedan emprender actividades productivas" es un "derecho que el Estado no puede ni debe eliminar conforme a los principios expuestos" (de la "concepción cristiana"). Considera que este es "el único camino que permite un desarrollo de la economía" (18). Es decir, combina una racionalidad teológica con una económica. Se expone inmediatamente el polo negativo, la "sociedad estatista" -regida por "el burócrata"- , que "no sólo... termina por negar prácticamente la libertad personal", porque la "centralización" es "excluyente de toda actividad económica", lo que "prescinde la capacidad creadora de los particulares en el terreno empresarial". Vincula así la "libertad personal" política y social con la eficiencia económica que posibilita el surgimiento de "nuevas fuentes de producción y trabajo" (18). La propiedad privada sobre "los bienes de consumo como sobre los medios de producción" (19), el "derecho de propiedad", es considerado "una consecuencia ineludible de la concepción del hombre y la sociedad antes esbozada", es decir, lo vincula a la "concepción cristiana". También al "principio de subsidiariedad que de ella se deriva".

Se pretende lograr "Un desarrollo económico acelerado, un efectivo progreso social y una escala de valores morales que los jerarquice respecto del hombre: metas indisolubles de la reconstrucción nacional" (33). Se aclara el lugar de la economía en las prioridades valóricas al expresar que "[l]a obtención de un acelerado desarrollo económico no puede, sin embargo, -operar- como un fin en sí" puesto que "[l]a riqueza nacional es sólo un medio para proporcionar bienestar a los habitantes del país en forma que éste alcance equitativamente a todos". Es el Estado el encargado de realizar el ajuste valórico mencionado para "ir transformando esa mayor riqueza ["los índices de crecimiento de la economía, del producto nacional o de la renta per cápita"] en progreso social" (34).

El "desarrollo social deberá distinguir lo que son verdaderas conquistas de los trabajadores, porque significan mayor progreso para el país y mayor justicia para ellos mismos, de las mal llamadas "conquistas" y que amparan situaciones de ocio o privilegio que un país como Chile no puede aceptar". En el "plano" de estas "conquistas" el Gobierno "concede especial relevancia al cuerpo legal", mencionando explícitamente el "Estatuto para la organización de las empresas, el desarrollo e integración de los trabajadores, el fomento y tratamiento de las inversiones", "en el que se 
establecerán fórmulas de efectiva participación de los trabajadores en las empresas que laboran, dentro del realismo y la flexibilidad que el tema impone por su compleja variedad y por la necesidad de contemplar también las garantías adecuadas a la inversión" (35).

\section{LAS TRANSFORMACIONES DOCTRINALES DEL GREMIALISMO EN LA NEOLIBERALIZA- ción del Régimen Cívico-Militar de Chile. 1973-1980}

\subsection{La subordinación de la Trascendencia}

a) Desde 1976 a 1978, las críticas de la Iglesia Católica chilena y de la ONU ante la masiva violación de los Derechos Humanos, y la necesidad de internacionalizar la economía que, por lo anterior, experimentaba dificultades, más las tensiones generadas por las elites civiles gremialistas para obtener mayores espacios de poder en el RCM, llevan a modificar el ejercicio de la violencia, que disminuye. La hegemonía Pinochet-Alto Mando del Ejército sufre un menoscabo por las consecuencias del crimen de Orlando Letelier en EEUU, país que presiona para someter a proceso al general Manuel Contreras, ex jefe de la DINA. También por la disidencia decisiva de uno de los integrantes de la Junta Militar, general Gustavo Leigh. Es el momento del primer triunfo del neoliberalismo, pues se piensa que la recesión económica ha quedado atrás. En éste contexto se redacta el Discurso de Chacarillas, predominando su proyección política. Trata débilmente la "concepción cristiana". En relación a la "espiritualidad" del hombre, se afirma que "Nuestra historia y nuestra idiosincrasia se han forjado en el respeto a la dignidad del hombre" (33), tema relacionado con los derechos humanos. Las referencias a la "patria" están en función de precisas consecuencias inmanentes: generar obediencia política y legitimar el gobierno. Como la DP, se afirma que es proyectada en la historia por el Gobierno por medio de las Fuerzas Armadas y de la Junta (33). El "pueblo" es, por momentos, sólo la "juventud" y en ellos recae fundamentalmente la conservación de la "patria", no en la mujer, como en la DP. No existen mayores referencias, a diferencia de la DP, a que el "hombre" alcance su realización en la familia y sociedades menores e intermedias.

La mención de los elementos "nacionalistas", sigue la orientación política mencionada. Se establece el vínculo Junta de Gobierno-nacionalismo-reconstrucción de la patria-unidad nacional $(6,30)$. La "nueva democracia" se define como "protegida" por cuanto lo está al "afianzar como doctrina fundamental del Estado de Chile el contenido básico de nuestra Declaración de Principios, reemplazando el Estado liberal clásico, ingenuo e inerme, por uno nuevo que este comprometido por la libertad y la dig- 
nidad del hombre y con los valores esenciales de la nacionalidad" (37). La "nueva institucionalidad" que se menciona sí es nacionalista pues, se afirma, "No se trata pues de una tarea de mera restauración, sino de una obra eminentemente creadora, sin perjuicio de que dicha creación, para ser fecunda, debe enraizarse en los signos profundos de nuestra auténtica y mejor tradición nacional" (37).

En los años 1979 y 1980 se superan las dificultades de los años 1977 1978, volviéndose a consolidar la hegemonía Pinochet-Alto Mando del Ejército, al institucionalizar mediante la Constitución de 1980 su poder, cautelando también el ejercicio de la violencia mediante la legalización de los presupuestos básicos de la Doctrina de Seguridad Nacional. Las disidencias en torno a la Carta Fundamental generan el desplazamiento de los gremialistas del poder, pero no de los neoliberales, que imponen su modelo con más profundidad buscando generar "modernizaciones sociales". En VFCH, generado en éste momento decisivo del RCM, se acude a la "concepción cristiana" para sustentarlo en cuanto trascendencia, amparándose directamente en la DP, evitando así mayores desarrollos. Se une el hombre a ella por su espiritualidad y, de esta forma, está por sobre el Estado, quien tiene que respetar el "Principio de Subsidiariedad". No existen mayores detalles intermedios o complementarios de los elementos trascendentes mencionados; la proyección buscada es concreta, en la inmanencia. Se afirma sobre la "concepción cristiana" que "[u]na visión global de la realidad nacional no puede omitir una referencia a la posición de lo religioso en la nueva constitucionalidad. Cita a la DP por ser explícita en este punto, validando así el legado de nuestra tradición occidental, humanista y cristiana, con la riqueza de un vigoroso sentido nacional, desprendiéndose de ello el reconocimiento de la espiritualidad y dignidad de la persona humana" $(22,47,50)$. La proyección inmanentista del uso de la concepción cristiana se refleja en la forma en que se trata el "peligro" en que está la "civilización occidental", pero sus efectos referidos no tienen relación con la "concepción cristiana". En 1979, el GCM es percibido como relativamente lejano en el tiempo $(3,4)$. El peligro se sitúa en el futuro y se vuelve una y otra vez a lo largo del documento sobre el peligro marxista y la necesidad de neutralizarlo $(4,33,34,41,42)$. Finalmente, se afirma que "[e]s tan grande y grave el peligro permanente, que no entendemos terminada nuestra misión y nuestro deber con la sola dictación de una nueva constitución, por elevada que sea la perfección técnica de sus normas" (49). Otro peligro que menciona VFCH es la oposición que existe al Presidente del país. Expresa el documento que "... desde el inicio mismo del régimen portaliano hasta hoy, los grandes enemigos del Presidente como institución, y de su poder, han sido los grupos de presión y las 
oligarquías. Estas han querido siempre gobernar por sí y para sí, viendo un obstáculo en su autoridad..."(6). Los elementos relacionados con la patria sólo se enuncian, pero su proyección temporal cercana, inmanente, instala también percepciones de crisis, peligro, amenazas. Los elementos básicos son que las Fuerzas Armadas se apropian del sentido tradicional de patria, aunque ésta forma parte del "alma" del "pueblo" y es la juventud quien garantiza su conservación. Se desplaza a la mujer, que tiene sólo un papel auxiliar, educador de la familia. Se sostiene: "Es igualmente indispensable estimular el desenvolvimiento de una nueva generación civil, impregnada de los referidos valores. Olvidar este aspecto capital ocasionaría que, al término del régimen militar, volviesen los mismos hombres y partidos cuyo fracaso exigió la intervención de las Fuerzas Armadas y ésta sería entonces algo efímero, sin raíces profundas en la evolución histórica de la Nación" $(50,51)$.

\section{2. El Estado ausente}

En el DCH se vuelve a las ideas de la DP. En el contexto posterior a 1977, este control del Estado evidencia que los militares corporativistas y el Comité Asesor de la Junta han perdido influencia frente a gremialistas y neoliberales quienes, a su vez, procuran despejar el campo social para la acción del mercado, sin interferencias. El Estado debe ser claramente delimitado en sus funciones y controlado. Coincide el DCH con la DP cuanto afirma que la "doctrina fundamental" del Estado está contenida en la Declaración de Principios del año 1974" (23), lo que significa que sigue los "principios" que la Junta establece, que no los elabora por sí mismo. También en cuanto a que el Estado, si bien es socialmente necesario, es percibido negativamente en función de su papel durante la U. P.

En el DCH se postula el reemplazo del "Estado liberal clásico, ingenuo e inerme, por uno nuevo" "comprometido por la libertad y dignidad del hombre y con los valores esenciales de la nacionalidad" (23). Sobre la afirmación de que el fin del Estado es el "bien común general", afirma que la "nueva democracia" que se postula es "de auténtica participación social" en la medida que "consagra y respeta una real autonomía de las agrupaciones intermedias entre el hombre y el Estado, para perseguir sus fines propios y específicos" pues, aunque la autoridad estatal fija reglas "para velar por el bien común", estas no deben asfixiar a las personas, pues se estaría en presencia de un "Estado omnipotente" (27). Sobre si el Estado debe asumir sólo las funciones que las sociedades menores e intermedias no puedan cumplir, indirectamente, lo afirma. Hay, por lo tanto coincidencias en algunos puntos con la DP. 
Se reconoce el papel del Estado al sostener que "[e]l énfasis que la nueva institucionalidad hace en el rol subsidiario del Estado no responde, pues, a forma alguna de teoría dogmática, sino a la necesidad de proteger de modo efectivo la libertad personal" (24). Pero se sigue desconfiando de él al afirmar que, en la labor de "promoción del bien común", "el derecho aparece como el principal instrumento de que dispone la autoridad, por contraposición a la intervención del Estado según el arbitrio o la necesidad contingente de quien detente el poder" (23). El "concepto de justicia" "remite" a "la organización de los poderes del Estado" y a sus "funciones" (34). Como es la Junta quien controla el Estado, entonces en ella radica la justicia.

VFCH coincide con la DP respecto a que el fin del Estado es el "bien común general" al afirmar que "[e]l bien común no es el bien del Estado ni tampoco el bien de la mayoría, o de una o más minorías. Bien común es aquel ordenamiento que brinda a todos y a cada uno de los hombres la posibilidad de obtener bienes individuales con respeto solidario y activo por el bien de los demás. Es una meta que orienta la acción del Estado, el cual debe acercarse a ella en la mejor forma posible, aun cuando su realización plena se dificulte por la imperfección humana" $(22,23)$. Se advierte, posteriormente: "Debo, eso sí, subrayar que en esa organización nueva, el Estado no será más un mecanismo neutro, susceptible de ser utilizado indistintamente por cualquier combinación de mayorías o minorías circunstanciales" $(35,36)$. VFCH también coincide plenamente con la DP respecto a que el Estado debe asumir sólo las funciones que las sociedades menores e intermedias no puedan cumplir al sostener que "...en el cuerpo social es requisito indispensable, para la existencia y subsistencia de una verdadera libertad, el respeto del principio de subsidiariedad, en virtud del cual el Estado debe asumir directamente sólo aquellas funciones que las sociedades intermedias o los particulares no pueden desempeñar adecuadamente, como es el caso del Orden Público, la Defensa Nacional, las Relaciones Exteriores y aquellos servicios o actividades estratégicas que requieren de una coordinación general, no accesible a otro órgano que no sea el estatal. Las demás funciones sociales sólo deben ser ejercidas por éste cuando las sociedades intermedias, no las realizan" (23).

No se refiere, pues ya no es necesaria esa puntualización, que el Estado deba seguir los "principios" de la Junta, no elaborarlos, sólo ejecutar. Tampoco, que debe desarrollar un "Proyecto Nacional" integrando la "Seguridad Nacional", el "Poder Nacional", lo que evidencia una ausencia de criterios de la DSN, al menos puntualmente, posiblemente por la pretensión gremialista de desplazarlos o minimizarlos de la futura Constitución, lo que finalmente no ocurrirá. 


\section{3. El Principio de Subsidiariedad neoliberal}

a) En DCH se sostiene que el principio de subsidiariedad "es la base de ...una libertad económica que, dentro de las reglas que fija la autoridad estatal para velar por el bien común, impida la asfixia de las personas por la férula de un Estado omnipotente (37). También, con algunas diferencias con la DP, -que afirma que se prioriza el desarrollo económico ("acelerado") por sobre los aspectos sociales y valóricos- afirma que "[f]rente al éxito ya perceptible del plan económico, el progreso en las medidas de orden social, y el orden y la tranquilidad que hoy brindan una vida pacífica a nuestros compatriotas, la atención se ha centrado ahora en mayor medida en nuestro futuro jurídico-institucional" (33). No se sostiene, como en 1974, que el desarrollo debe alcanzar equitativamente a todos, que el Estado debe considerar el bien común y el principio de subsidiariedad, planificar la actividad económica, asegurar la competencia y controlar a los particulares, ser el propietario de los bienes estratégicos. No se habla sobre el trabajo, respecto a ser un vehículo de desarrollo económico y a la existencia de un "desafío" que supone jerarquía y disciplina en las tareas productivas y en los hábitos de trabajo. No se afirma que sea el Gobierno el que propone "las verdaderas conquistas de los trabajadores" (un "estatuto").

Ya es evidente una transformación de cuanto se ha afirmado respecto al papel del Estado en la instauración de justicia social. Casi nada se habla de la relación Estado-bien común-principio de subsidiariedad. Sobre el último, sólo afirma que "es la base de un cuerpo social dotado de vitalidad" (37).

Respecto a la definición de bien común, VFCH casi coincide con la DP en este punto, en cuanto al enunciado mismo, no en el contexto económico-social que el gobierno desarrolla, que contradice estas afirmaciones. Afirma que "[e]l bien común no es el bien del Estado ni tampoco el bien de la mayoría, o de una o más minorías. Bien común es aquel ordenamiento que brinda a todos y a cada uno de los hombres la posibilidad de obtener bienes individuales con respeto solidario y activo por el bien de los demás" $(22,23)$. No es referido que no puede alcanzarse plenamente "su verdadero bien individual". Es de esta forma como la afirmación de la DP de que el desarrollo debe alcanzar equitativamente a todos es también sostenida en VFCH. Se expresa que el Estado debe considerar el bien común y el Principio de Subsidiariedad y, también, respetar el derecho a la libre iniciativa económica y su propiedad privada, la que se vincula a elementos trascendentes que no se habían mencionado en el DCH. VFCH afirma que es el respeto al Principio de Subsidiariedad "el que involucra la aceptación del derecho de propiedad privada y de la libre iniciativa en el campo económico, que consideramos como la única vía que conduce 
a un verdadero desarrollo". "La absorción estatista y centralizadora de la actividad económica tiene como consecuencia inevitable no sólo el estancamiento del progreso, sino también la rápida pérdida del campo de acción independiente de la persona. En la misma medida en que el Estado asume el control de la actividad económica desaparece igualmente la libertad individual, que puede considerarse extinguida desde el momento en que el Estado controla el consumo. Evidencia de ello se encuentra en los regímenes que han abolido la propiedad y la iniciativa privada" $(23,24)$. Agrega: "...la consecución del bien común presupone el reconocimiento de los aludidos derechos de propiedad e iniciativa personal, sobre cuya base habrá de erigirse el orden económico. Sin incurrir en excesos deterministas, podemos señalar que en la interrelación entre el ordenamiento económico y el orden social y político, la libertad económica es un requisito necesario para la existencia de un sistema político realmente libertario. No significa esto que la Carta Fundamental deba quedar ligada a un determinada política económica, pero sí implica que aquélla contenga las normas básicas sustentadoras de la actividad económica, conformando un sistema coherente que respete e incentive la libertad individual y el principio de subsidiariedad" (24). No se descuida, por lo tanto el desarrollo económico y, como en la DP, lo prioriza por sobre los aspectos sociales y valóricos. En VFCH se expresa que el "Plan Económico es el que ha permitido, por ejemplo, entre otros benéficos efectos, contener la inflación, incrementar las importaciones y exportaciones, o rescatar a nuestra Patria de la ignominiosa situación de cesación de pagos de sus deudas". Agrega: "[c]onduce directamente al mayor bienestar de todos los chilenos, en particular de aquellos sectores laborales antes más postergados, a través del innegable crecimiento económico" y que "En menos de un sexenio, hostilizado desde todos los frentes, nuestro Gobierno ha sido capaz, sin embargo, de echar las bases para un desarrollo cuyos beneficios iniciales ya pueden percibirse en forma evidente" (46). "Es desde todo de vista necesario que exista un efectivo receso político, para lograr que el saneamiento económico alcanzado se traduzca en un desarrollo sostenido, que ofrezca mayor bienestar para todos los chilenos, y para que se afiance en un nuevo modelo social, congruente con la institucionalidad de una sociedad verdaderamente libre" (50). Los aspectos sociales quedan supeditados a lo económico y los valóricos no son mayormente mencionados. Se afirma, en todo caso: "Respecto al bienestar espiritual y material, las consideraciones precedentes en torno a la libertad y al derecho de propiedad son orientación suficiente dentro del marco de esta exposición" (34).

Algunos términos de la DP son aquí utilizados, como el Principio de Subsidiariedad, pero proyectados de forma distinta, lo que los modifica 
radicalmente. Por ello, la solidaridad y el bien común plantean una democracia que sólo en una apariencia terminológica es similar a aquella con resabios de justicia social que vimos en la DP. Para los neoliberales, la justicia social y la igualdad son visualizadas como ausencia de la discriminación del intervencionismo estatal y político, pues el mercado distribuye la oportunidad en función del talento y esfuerzo de cada uno, condenándose las conquistas sociales otorgadas por el Estado Benefactor y desplazándose la igualdad social concebida como responsabilidad social por una que es tarea individual. Sin embargo, los neoliberales aspiran a la justicia social que se realiza cuando no operan elementos que impidan la reciprocidad en las transacciones; por ello, triunfan los más capaces y esforzados y se impulsa la actividad creadora y se valoriza la superación personal, lo que da sentido a la moral del esfuerzo y al cumplimiento del deber. El orden de mercado castiga a los que se equivocan, a los ignorantes e incapaces y a los que no cumplen los contratos, que es, precisamente, lo que, suponen, el socialismo premiaría al favorecer a los que temen al mercado y se amparan en el Estado y en los favoritismos políticos. Con lo anterior, se critica la democracia tradicional, que desaparece como ideal ético político para convertirse en un medio para organizar una sociedad libre -aquella donde se respeta la libertad del mercado y la igualdad de los individuos ante él-, lo que hace compatible el autoritarismo con la economía liberal, pues mientras no se concreten los cambios económicos no estarían constituidas las bases para una democracia sólida. De esta forma, el autoritarismo no es transitorio sino constitutivo de una sociedad libre. Por ello los neoliberales critican el intervencionismo estatal en los planos económico y social pero no político.

Es incompatible con el predominio neoliberal sostener el fortalecimiento de la autonomía de los cuerpos intermedios ("poder social"), el reconocimiento a la persona humana de derechos naturales anteriores al Estado, la ideología laboral participacionista, integrativa. Se comienza a plantear a la subsidiariedad como condición de libertad individual y a la autoridad impersonal portaliana como garantía de igualdad ante la ley. La verdadera libertad individual es la que propicia el mercado y esta es la base de la libertad política, lo que lleva a reformular la subsidiariedad, pues su respeto ahora exige minimizar el papel del Estado, que es visto como un totalitarismo, e implementar una economía de libre mercado. Es el mercado y no la sociedad donde se difunden y socializan el poder y las oportunidades por lo que cualquier propuesta limitante de éste es presentada como una restricción a la libertad personal (Vergara, 1985: 88-92).

La proyección trascendente neoliberal es diferente, pues su programa económico se fundamenta en un saber de carácter científico, la ciencia 
económica moderna, por lo que para ellos las críticas a la política económica serían fruto de la ignorancia o la defensa de intereses particulares. Se genera una concepción tecnocrática del poder que sacraliza a los expertos, quienes son los únicos capaces de conducir a la sociedad hacia un nuevo orden. No se incluye a los gremios -a los que la DP otorga valor para consultarlos- cuya participación se convierte en un obstáculo, pues defienden sólo intereses parciales y no universales. De igual forma se ven los planeamientos de toda organización corporativa o política. Sin embargo, es esta suerte de creencia en la cientificidad de sus planteamientos la que, precisamente, les otorga un tono trascendente, uno en que la terminología a ratos es diferente, de corte económico, aunque recogiendo la de la DP, variando su significado. Por ello, si bien hay alusiones a anteriores elementos, por mucho que los gremialistas los hayan adaptado conceptualmente a los requerimientos de las percepciones tecnocráticas del poder, estos quedan sin un fondo significativo trascendente sólido. Sin duda, deben usarse, porque remiten a conceptos que, por provenir, al menos, de la DP, otorgan una consistencia temporal conceptual al régimen $y$, en cuanto a la hermandad de formación gremialista-neoliberal de la década del sesenta, mantienen una estructura de significación que permite su pervivencia y unidad de sentido. Por ejemplo, cuando José Piñera expresa en diciembre de 1980 que el régimen militar haría la última revolución, la libertaria, aquella que al arrebatar el poder al Estado y devolverlo a los individuos, terminaría con todas las revoluciones (Vergara, 1985: 99, 100), no quiere con ello significar igual sentido de revolución que el planteado en la DP en 1974. La base doctrinal trascendente de cada uno es distinta.

b) El DCH coincide con la DP al afirmar que la "nueva democracia" es de "auténtica participación social, en cuanto a que sólo es verdaderamente libre una sociedad que, fundada en el principio de subsidiariedad, consagra y respeta una real autonomía de las agrupaciones intermedias entre el hombre y el Estado, para perseguir sus fines propios y específicos" (37). Se detalla más la forma que el vínculo poder social-gremio-principio de subsidiariedad adquirirá en el marco institucional en cuanto composición de la Cámara Legislativa (39-44). Esta proyección política desaparece casi dos años después en VFCH, en un contexto de pleno dominio neoliberal. Los criterios gremialistas trascendentes $y$, definitivamente, los criterios corporativistas de los militares, se ausentan. Es una adaptación definitiva a las necesidades conceptuales neoliberales. Los conceptos de la DP, "poder político" y "poder social", no son mencionados. Indirectamente, se sostiene, respecto al segundo, que "...en el cuerpo social es requisito indispensable, para la existencia y subsistencia de una verdadera libertad, 
el respeto del principio de subsidiariedad, en virtud del cual el Estado debe asumir directamente sólo aquellas funciones que las sociedades intermedias - los particulares no pueden desempeñar adecuadamente... [l]as demás funciones sociales sólo deben ser ejercidas por éste cuando las sociedades intermedias, por negligencia o por fallas, no las realizan" (23). No se refiere, a que el "hombre" alcance su realización en la familia y sociedades menores e intermedias. Tampoco el DCH y VFCH se refieren a los gremios, aunque el último sostiene que "...en el cuerpo social es requisito indispensable, para la existencia y subsistencia de una verdadera libertad, el respeto del principio de subsidiariedad, en virtud del cual el Estado debe asumir directamente sólo aquellas funciones que las sociedades intermedias o los particulares no pueden desempeñar adecuadamente, como es el caso del Orden Público, la Defensa Nacional, las Relaciones Exteriores y aquellos servicios o actividades estratégicas que requieren de una coordinación general, no accesible a otro órgano que no sea el estatal. Las demás funciones sociales sólo deben ser ejercidas por éste cuando las sociedades intermedias, por negligencia o por fallas, no las realizan" (23).

Estos silencios evidencian la ausencia de las ideas gremialistas, o bien su adaptación a las pautas neoliberales. Estas se van quedando sin un discurso político global para justificar en términos de universalidad el autoritarismo político y la revolución capitalista y sus costos sociales. Ya en 1975 adquieren primacía en su discurso los elementos de la Doctrina de Seguridad Nacional, la crisis económica y la institucionalización de carácter legalista. Basado en la concepción humanista y cristiana del hombre y la sociedad, habían postulado una sociedad civil fuerte y organizada, con cuerpos intermedios autónomos y despolitizados, que configuraban el poder social, el supuesto marco de contención del poder político. No se concebía, como los neoliberales, una sociedad des-organizada constituida por individuos atomizados, con organizaciones intermedias débiles y competitivas entre sí. Pero deben adaptar algunas nociones a este pensamiento, como la libertad individual e igualdad económica como metas últimas de la sociedad. Se insiste en que siguen inspirados en la DP, pero sus conceptos centrales, como el principio de subsidiariedad y la autonomía de los cuerpos intermedios, son reinterpretados, pues ahora se deben redefinir en función del papel que asignan los neoliberales al Estado y al mercado y al desmontaje de las organizaciones sociales que realizan. Por ello, tratan de justificar el individualismo expresando que los cuerpos intermedios fueron necesarios cuando se defendía la libertad de un Estado omnipotente y que debe ser la genuina expresión de la libre voluntad de sus asociados lo que revitalice su papel, pero así se despoja al gremio de sus anteriores poderes monopólicos, pasando su representación a depender de su capacidad 
para atraer el interés de sus asociados. De esta forma, el poder social no puede ser efectivo, ni originar una sociedad orgánica y fuerte (Vergara, 1985: 168-172). Esta variación, es la que recogen el DCH, VFCH y la Constitución de 1980, que sostiene en su artículo $1^{\circ}$ que el Estado reconoce y ampara a los grupos intermedios a través de los cuales se organiza y estructura la sociedad, garantizándoles la adecuada autonomía para cumplir sus propios fines específicos. Pero cada sociedad intermedia posee autonomía relativa, pues el Estado actúa cuando en el cumplimiento de sus objetivos se alejan del bien común, según lo plantea el Principio de Subsidiariedad; o cuando las sociedades mayores amenazan su autonomía. Así, se les separa del mundo político y controla desde el gobierno.

VFCH no explicita el lenguaje de la DP que utiliza, otorgándole, sin embargo, otro significado. Se podría afirmar que ello se debe a la confianza que se tiene de que la elite gobernante esté suficientemente informada de su ideario y sepa establecer las diferencias, aunque es probable que, olvidando los contenidos de la DP o reinterpretándolos en una dirección neoliberal, o una combinación de ambos, esta sea capaz de realizar el ajuste. Los escritos de Jaime Guzmán en la revista Realidad son esenciales en esta transformación. Tenemos la impresión de que es el carácter trascendente de la DP el que, al no ser explicitado ni en el DCH ni en VFCH, constituye un aspecto fundamental en la transformación mencionada. Se privilegian los elementos inmanentes, que aparecen como la base que sustenta el sistema, al expresar que "[l]a institucionalidad, es mucho más vasta, y su renovación exige modificaciones sustanciales en materias tales como el campo laboral, provisional, educacional, económico, de salud, viviendas, y otras igualmente determinantes" (26). También ello se evidencia con la afirmación de que la "nueva institucionalidad no es un fin en sí, sino un medio para la consecución de los valores ya citados", lo que significa que es el sustento material proveniente del mercado el que origina los valores, no que estos provengan de un origen trascendente. Esta diferencia es central con respecto a la DP, pues, entre otros motivos, el carácter de "cruzada" de entonces ha desaparecido definitivamente hacia 1979, derivándose consecuencias importantes para el funcionamiento del sistema; por ejemplo, respecto al carácter "solidario" que proyecta el bien común, que mira a la preocupación por el otro, con un amparo trascendente, según se estableció en la DP. Distinta es la proyección de VFCH, inmanente, cuando procura sustentar un cambio en la "mentalidad oprimida" en los jóvenes para "desarrollar y personificar hábitos cívicos renovados formados en el valor del esfuerzo y de la creación personal", puesto que este proceso debía ser claramente dirigido por un sistema educacional que, en apariencia, estaba abierto a todos, pero que, en realidad, favorecía a quie- 
nes pudieran acudir a establecimientos privados que ofrecerían una mejor educación, dado su acceso a mayores recursos y a los que se le quitarían a la educación pública. Se mantenía la existencia de una elite conductora de la sociedad, pero encubiertamente. Se obtendría la despolitización al evitar la gratuidad, creadora de "activismo", pero se piensa que el Estado seguiría haciendo justicia social al formar "soberanos" o personas que sólo supieran leer, escribir y hacer cálculos básicos. Se opta por el individualismo despolitizador, por una sociedad jerárquica, pero aparentemente democrática (Valdivia, 2003: 239). Así, el neoliberalismo, al apropiarse de la democracia clásica, fundamentaba el autoritarismo político, en un lenguaje que parecía cercano a las tradiciones políticas chilenas, a diferencia del tradicionalismo católico y la DSN que generaban poco atractivo fuera del mundo militar. Sin embargo existen algunas contradicciones en VFCH con el neoliberalismo imperante, pues ellos creen que la estabilidad social depende de mecanismos de coordinación, que son generados por el mercado, no por la pura fuerza o la voluntad política. Critican la ideología institucionalizadora (constitucionalista, decisionista), centrada en preservar el equilibrio político más que en establecer reformas revolucionarias para generar un orden nuevo, lo que expone al nuevo sistema jurídico a convertirse en letra muerta 0 a derivar a otra realidad que la concebida (Vergara, 1985: 153, 159, 160). Pero se ha visto que el documento insiste en no poca medida en la "institucionalización" del DCH. Se piensa que ello se debe a que los redactores de VFCH no necesariamente coinciden plenamente con estas elites. Por ello, se perciben divergencias importantes al interior del régimen, que posiblemente se prolongarán hasta los últimos instantes en que se defina la Constitución de 1980. Pese a lo anterior, lo que se impone finalmente es un autoritarismo con tutela militar, funcional al neoliberalismo y, en menor medida, al pensamiento conservador de la DP, que ya se ha transformado.

\section{Conclusiones}

La variedad y dispersión temporal de los elementos semánticos presentes en los documentos oficiales del RCM estudiados determinan que sus dispositivos de poder discursivos carezcan de coherencia doctrinal en el período 1973-1980, porque los contextos cambiantes exigen adecuaciones e innovaciones doctrinales. Sin embargo, si se considera que los documentos oficiales posteriores a 1974 utilizan en no poca medida los mismos términos de la DP, es éste documento quien otorga continuidad ideológica, aunque en el nuevo marco conceptual neoliberal su significado es distinto. Ello marca una permanencia y una variación al mismo tiempo, principalmente por el uso constante de elementos trascendentes, especialmente notorios en 
la DP y VFCH, lo que otorga coherencia simbólica en el largo plazo, más allá de la coyuntura puntual. Es un soporte emocional básico, una salida al miedo que otorga seguridad, al que se apela cuando se está en una instancia de cambio más o menos radical del régimen y este necesita adecuar su producción de sentido, lo que puede generarle disensos que perturben sus dispositivos de poder obedienciales. Se apela entonces a la coherencia simbólica por sobre la doctrinal para lograr una aprensión emocional de contenidos trascendentes, a los que se vinculan los inmanentes políticos y económicos. Si se piensa en que el redactor principal de estos documentos fue Jaime Guzmán, de intensa vida religiosa, la influencia de estos presupuestos gremialistas en la DP se convierte en decisiva.

Los contenidos trascendentes percibidos en el pensamiento de los gremialistas antes de 1977 llevan a pensar en la existencia de un instinto de sobrevivencia dependiente de percepciones simbólicas, donde la "concepción cristiana", la "patria" o la "nación" están en "peligro", operando el "instinto mítico" en función de un phobos, un miedo irracional y descontrolado (André, 2005: 21). Los neoliberales, en cambio, muestran un soporte trascendente menos vital, en términos de un arraigo de larga data, colonial, que conforme una mentalidad como los primeros, lo que invalida el uso del concepto "instinto", "mítico" en este caso, para tipificar su sobrevivencia. El transito gremialista desde pautas conservadoras trascendentes observables en la DP hacia estas formas muestra que, ante el predominio de las pautas de la Doctrina de Seguridad Nacional militares y del pensamiento neoliberal, el gremialismo se suma, en cuanto dispositivo de poder discursivo, a la concepción de una militarización de la política destinada a controlar la irrupción inesperada de elementos históricos no contemplados en el monopolio político y jurídico que se ejerce. También, a una tecnologización de la economía y sociedad, por lo cual renuncia a sus perspectivas corporativas $y$, especialmente, a su proyecciones trascendentes.

\section{Biblografía}

Fuentes primarias

CONSTITUCIÓN DE 1980. Editorial Jurídica de Chile. Santiago de Chile, 1981.

DECLARACIÓN DE PRINCIPIOS DEL GOBIERNO DE CHILE. Editora Nacional Gabriela Mistral. Santiago de Chile, 11 de marzo, 1974.

DISCURSO DE CHACARILLAS. Diario El Mercurio. 10 de julio, 1977. VISIÓN FUTURA DE CHILE. División Nacional de Comunicación Social, Santiago de Chile, abril, 1979. 
Fuentes secundarias

ANDRÉ, C. (2005): Psicología del miedo. Temores, angustias, fobias. Editorial Kairos, Barcelona, p. 21.

ARRIAGADA, G. (1998): Por la Razón o la Fuerza. Editorial Sudamericana, Santiago, pp. 77.

BRAUDEL, F. (1984): Civilización Material, Economía y Capitalismo. Volumen II. Alianza Editorial, Madrid, pp. 55-59.

CAÑAS, E. (1997): Proceso Político en Chile. 1973-1990. Editorial Andrés Bello, Santiago, pp. 64, 65.

CRISTI, R., RUIZ, C. (1992): El Pensamiento Conservador en Chile. Editorial Universitaria, Santiago, p. 37.

HUNEEUS, C. (2000): El Régimen de Pinochet. Editorial Sudamericana Santiago, pp. 378. 56, 73, 248, 249.

HUNEEUS, C. (2001): "La Derecha en el Chile Después de Pinochet: el Caso de la Unión Demócrata Independiente". Working Paper \# 285, p. 17.

MELLER, P. (1998): Un Siglo de Economía Política Chilena (1890-1990). Editorial Andrés Bello, Santiago, pp. 198-217.

PELLEGRINO, U. (1983): Diccionario Teológico Interdisciplinar. Volumen IV, Salamanca, Ediciones. Sígueme, pp. 543-555.

VALDIVIA, V. (2003): El Golpe Después del Golpe. Leigh vs. Pinochet. Chile 1960-1980.LOM Ediciones, Santiago, pp. 201, 239.

VERGARA, P. (1985): Auge y Caída del Neoliberalismo en Chile. FLACSO, Santiago, pp. 60, 88-92-100, 153-191. 